\title{
Audit of Epilepsy Clinics in South East Thames: Are We NICE?
}

\author{
Somnath Banerjee, Sanjay Sahi \\ School and Child Health, Queens House, Kent, UK \\ E-mail: somnath.b@doctors.org.uk \\ Received March 28, 2011; revised April 14, 2011; accepted April 16, 2011
}

\begin{abstract}
Background: NICE has suggested that paediatric epilepsy services should undergo regular audit. An audit was done to gain a snapshot across South East Thames clinics. Method: Audit in South East Thames was conducted in 2010. Results: In $86.5 \%$ seizure classification and in $42.8 \%$ a syndromic diagnosis was made. cQT interval was calculated in $10.1 \%$ cases and $91.8 \%$ had an EEG. In $48.5 \%$ adverse effects of drugs were communicated. $41.3 \%$ were given information leaflets/directed to the appropriate website. In $70.7 \%$ developmental/academic progress was documented. $61 \%$ had a written care plan. $70.2 \%$ had the copy letter to parents/carers whereas it was sent to School \& Child Health in $35.1 \%$. 23.1\% had access to specialist epilepsy nurse. Conclusions: This audit was a snapshot. The results showed that the care of children with epilepsy is consistent with the NICE guidelines in many aspects but patchy in the UK.
\end{abstract}

Keywords: Epilepsy in Children, Audit, NICE, SETPEG

\section{Introduction}

The National Institute for Health and Clinical Excellence (NICE) has issued guidelines for diagnosis and management of epilepsy [1]. NICE was set up as a special health authority for England and Wales in 1999 [2]. It is an independent organisation responsible for providing national guidance on treatments and care in the National Health Service (NHS) in England and Wales. South East Thames Paediatric Epilepsy Group (SETPEG) has also produced guidelines, based on best available evidence for the local clinics run by SETPEG member [3]. There is also guidance from the Joint Epilepsy Council Good Practice Initiative [4]. All the guidelines have made recommendations that paediatric epilepsy services should undergo regular audit. A multidisciplinary audit was conducted in South East Thames in 2010.

\section{Aims and Objectives}

The primary aim of this audit was to measure current practices against NICE and local guidelines and to gain an initial snapshot of some aspects of service quality across South East Thames. It is hoped that the findings will be able to contribute positively to the proposed national Epilepsy 12 audit in UK, due to commence in late
2011.

\section{Audit Standards}

For the purpose of this audit the standards were set against the NICE and SETPEG guidelines in the following categories:

1) All patients with epilepsy have a multi-axial seizure classification and syndromic diagnosis if possible.

2) Corrected QT interval is calculated in cases of diagnostic uncertainty.

3) EEG is arranged for all children attending epilepsy clinic.

4) Patients and carers receive appropriate information about adverse effect of anti epileptic drugs.

5) Patients and carers are provided with information leaflets or directed to appropriate websites for information.

6) The records show that developmental/academic progress of the patients is documented.

7) All correspondences from the clinic to GPs are copied to parents/carers and school health (with parental consent).

8) All children with epilepsy should have a written care plan.

9) All children should have access to an epilepsy nurse 
specialist.

\section{Methodology}

\subsection{Design}

A case note review to audit existing practices in the epilepsy clinics. Information recorded from the last clinic letter was used for data collection. The audit proposal \& data capture form were reviewed and approved by the SETPEG working group.

\subsection{Setting and Data Source}

Epilepsy clinics at secondary level in South East Thames run by the paediatricians with an interest in epilepsy, who were members of SETPEG.

\subsection{Inclusion Criteria}

- Patients must have been diagnosed after $2^{\text {nd }}$ January 2005.

- Attending follow ups for at least 12 months at the time of data capture.

- Data collected from Monday $1^{\text {st }}$ February 2010 to Friday $26^{\text {th }}$ March 2010 (eight weeks).

- Aged 17 years or under at the time of referral.

\subsection{Exclusion Criteria}

- Follow ups outside the set dates.

- Age 18 years or over.

- Diagnosed before January 2005.

\subsection{Data Protection and Caldicott Principles}

The sharing of information for this audit did not breach Data Protection or the Caldicott Principles. The information collected was confined to such data as should be shared between multi-disciplinary agencies working within the NHS and the Community. The database, for the purposes of this review, did not contain any patient identifiers. The permission for this audit was obtained from the clinical audit department.

\subsection{Case Identification}

Patients attending clinics with a diagnosis of epilepsy from $1^{\text {st }}$ February 2010. Cases were identified by a clinician in the clinic who extracted the data from the files. Appendix 1 is the data capture form used for this audit. Children's notes were audited one year after the diagnosis of epilepsy. This is because after the publication of a NICE guideline, National Health Service (NHS) organi- sations in the UK has three months period to implement NICE recommendations. For example, if a child was given the diagnosis in March 2009 then her/his notes were included for the audit purposes after March 2010. This was to make sure that an appropriate multi-axial diagnosis could be made.

\section{Results}

After exclusion of cases not meeting the criteria, 208 set of case notes were audited from nine Trusts (Table 1). There were $112(53.8 \%)$ boys and 93 (44.7\%) girls. No information was available in the data capture form for 3 $(1.4 \%) .17(8.2 \%)$ children were in the age range from 1 to 3 years, $82(39.4 \%)$ were of primary school age (between 4 to 10 years) and $79(38 \%)$ children were of secondary school age (11 to 17 years). No information was available in $30(14.4 \%)$ forms. The diagnosis of epilepsy was clear in $86 \%$ cases. The seizure classification was done in $86.5 \%$ and $42.8 \%$ had a syndromic diagnosis. EEG was done in $91.8 \%$ of cases. Adverse effects of antiepileptic drugs were communicated in $48.5 \%$ and in $41.3 \%$ cases either informative leaflets on epilepsy were provided or directed to the appropriate website. Developmental/academic progress was documented in $70.7 \%$. $70.2 \%$ cases had a written care plan. In $70.2 \%$ cases, the parents/carers were copied the clinic letter whereas it was copied to school health team in $35.1 \%$ cases. The access to the specialist epilepsy nurse was noted in $23.1 \%$. Figure 1 describes the detailed results of this audit.

\section{Discussion}

This audit demonstrated that when a child is advised to

Table 1. Participating trusts and number of patients recruited.

\begin{tabular}{clc}
\hline No & \multicolumn{1}{c}{ Trust } & $\begin{array}{c}\text { Number of recruits } \\
\text { (percentage, \%) }\end{array}$ \\
\hline 1 & East Kent Hospitals & $52(25)$ \\
2 & Queen Mary Hospital Sidcup & $52(25)$ \\
3 & Conquest Hospital Hastings & $28(13.5)$ \\
4 & Queen Elizabeth Hospital London & $28(13.5)$ \\
5 & Evelina Children Hospital & $22(10.6)$ \\
6 & South Downs & $14(6.7)$ \\
7 & Lewisham Hospital & $6(2.9)$ \\
8 & Princess Royal Bromley & $5(2.4)$ \\
9 & Brighton \& Hove & $1(0.4)$ \\
Total & Nine trusts & $\mathbf{2 0 8 ( 1 0 0 )}$ \\
\hline
\end{tabular}




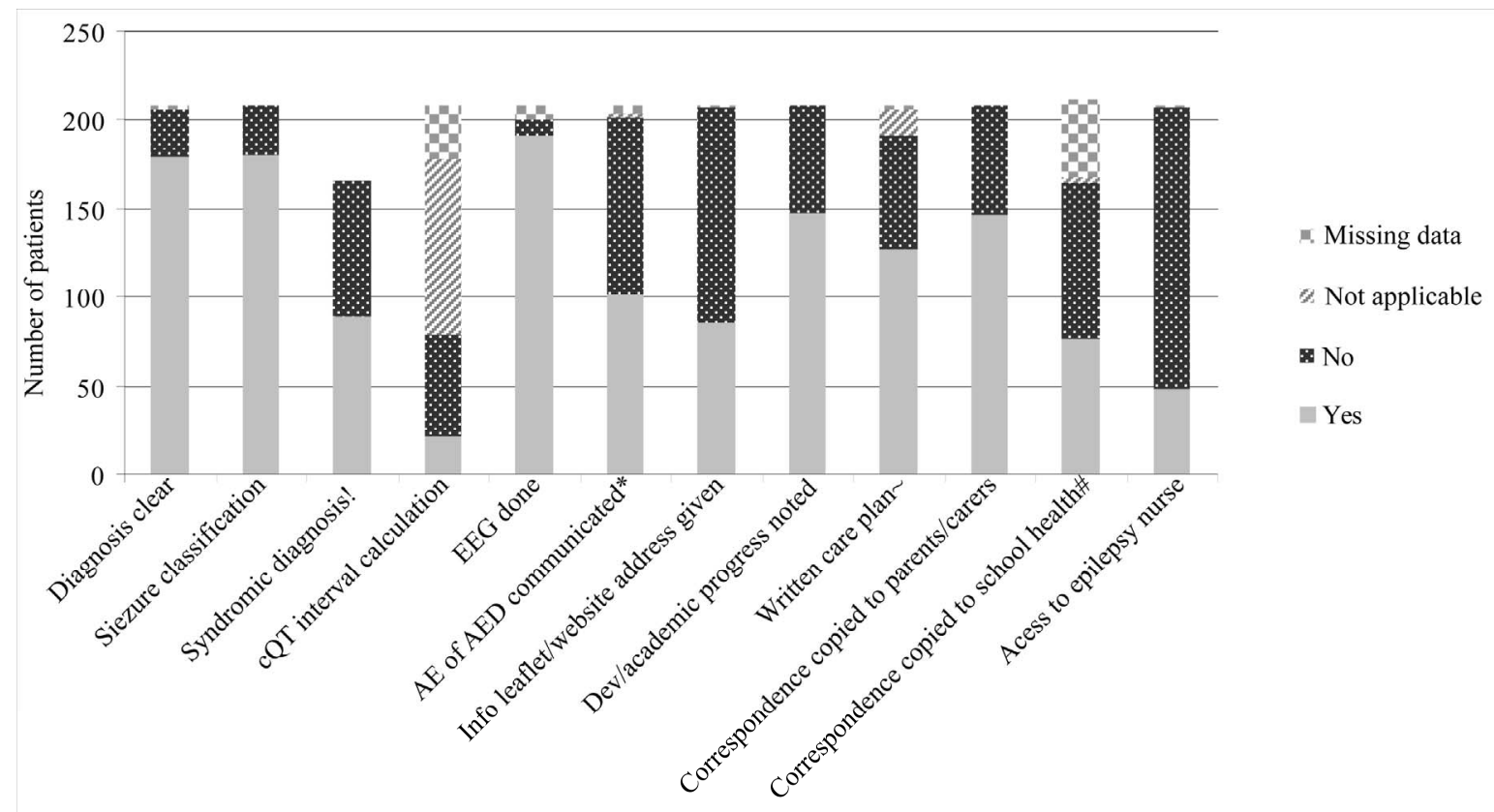

Figure 1. Setpeg audit results. ! = In another $42(20.2 \%)$, a syndromic diagnosis was attempted; $*=2$ children were not on any AED; 15 cases had well-controlled epilepsy so a written care plan was not needed; \# = 4 children were not in school.

have an antiepileptic drug, the child (if appropriate) and parents/carers needs to be told of the possible side-effects of medication/s and this should be documented in the notes. Children and parents/carers should be given written literature on epilepsy or directed to the appropriate website. Studies have shown that it is important for the physician to give information about the medication as this improves compliance $[5,6]$. The patient's developmental/academic progress should be documented in the notes. Children with a diagnosis of epilepsy should have a written care plan. The clinic letters of each visit should be copied to parents/carers and the local school and child health team. Individuals with epilepsy should be provided the appropriate information and contact details of the support services and referred to the epilepsy nurse specialist. In this audit, the majority of cases did not have access to epilepsy nurse specialist.

A level three diagnosis (i.e. syndromic diagnosis) should be made whenever possible. If not, level two should be attained (e.g. seizure type/s). A diagnosis of epilepsy is very rarely if ever, justified [4]. In case of diagnostic uncertainty a 12-lead ECG should be carried out in children [1]. Children presenting with seizure, collapse or a worrying history needs calculation of corrected QT interval $(\mathrm{QTc}=\mathrm{QT} / \sqrt{\mathrm{RR}})$ and referral to the cardiologist [3]. Incomplete data capture forms were noted to be a common error. Implementation of national clinical guidelines is the responsibility of each NHS board and is an essential part of clinical governance [7].
As a direct result of this audit a standardized proforma at first and subsequent clinic visits including investigations, multi-axial classification, and information and care plan checklists are now available in SETPEG website for the members. A leaflet for parents which aims to empower them to ask questions and provides details of further sources of information is also available in the website. The results of this audit have been made available to the national epilepsy 12 audit due to commence later this year and commissioned by Health Quality Improvement Partnership, Royal College of Paediatrics and Child Health, British Paediatric Neurology Association, British Society for Clinical Neurophysiology, Royal College of Nursing, Epilepsy Scotland, Epilepsy action and Quality Improvement Scotland.

\section{Recommendations}

1) More stress on syndromic diagnosis needed.

2) Corrected QT interval is calculated in diagnostic uncertainty.

3) Adverse effects of anti-epileptic drugs need to be communicated to patents and parents/carers.

4) Information leaflets/appropriate website addresses should be given to parents/carers.

5) Developmental/academic progress should be documented in the notes.

6) A written care plan should be in place.

7) Copy of the clinic letter of each clinic visit to be 
sent to School \& Child Health.

8) Access to the specialist epilepsy nurse needs to be universal.

\section{Acknowledgements}

Authors are grateful to the SETPEG members who completed the data capture form for this audit.

\section{References}

[1] National Institute of Clinical Excellence, "The Epilepsies: Diagnosis and Management of the Epilepsies in Children and Young People in Primary and Secondary Care," Clinical Guideline 20, 2004. www.nice.org.uk

[2] J. Raftery, "NICE: Faster Access to Modern Treatments? Analysis of Guidance on Health Technologies," British Medical Journal, Vol. 323, No. 7324, 2001, pp. 300-303. doi:10.1136/bmj.323.7324.1300

[3] E. Hughes and R. Williams, "Epilepsy Guidelines," South East Paediatric Epilepsy Interest Group, London, 2007. www.setpeg.co.uk

[4] S. Frost, P. Crawford, S. Mera and B. Chappell, "National Statement of Good Practice for the Treatment and Care of People Who Have Epilepsy," Joint Epilepsy Council, 2002.

[5] D. Webb, H. Coleman, A. Fielder and C. Kennedy, "An Audit of Paediatric Epilepsy Care," Archives of Disease in Childhood, Vol. 79, No. 2, 1998, pp. 145-148. doi:10.1136/adc.79.2.145

[6] A. A. Asadi-Pooya, "Drug Compliance of Children and Adolescents with Epilepsy," Seizure, Vol. 14, No. 6, 2005, pp. 393-395.

[7] Scottish Intercollegiate Guidelines Network, "Diagnosis and Management of Epilepsies in Children and Young People. A National Clinical Guideline 81,” 2005. http://www.sign.uk 
Appendix 1

\section{Audit on Epilepsy in the Paediatric Clinics in South Thames East}

\section{Demography}

Q. 1

Q. 2

Q. 3

Site

Age of the child

Gender:

Male

Female

\section{Standard I}

Q. 4.1

Q. 4.2

Seizure classification

Yes

No

Syndromic diagnosis

Yes

Attempted

\section{Standard II}

Q. 5.1

Q. 5.2

Q. 5.3

\section{Standard III}

Q. 6

Adverse Effects of drugs communicated

Yes

No

Standard IV

Q. 7

Information Leaflets provided or directed to appropriate website for information Yes

No

Standard V

Q. 8

Developmental/academic progress documented

Yes

No

\section{Standard VI}

Q. 9.1

Q. 9.2

Q. 9.3

\section{Written care plan}

Yes $\quad \square \quad$ No

NA

Correspondence copied to parents

Yes

Correspondences copied to school health team

Yes

No

No

\section{Standard VII}

Q. 10

Access to epilepsy nurse specialist

Yes

No

Thank you for completing this form. Please return to: Dr S Banerjee, Community Paediatrician, School \& Child Health, Queens House, Queen Street, Ramsgate, Kent CT11 9DH by Wednesday 15 April 2010. 